\title{
Chapter 10 Water Integrity: From Concept to Practice
}

\author{
Håkan Tropp, Alejandro Jiménez, and Hélène Le Deunff
}

\begin{abstract}
The adherence of water stakeholders and institutions to integrity principles is critical to improve water governance and sustainable water development. Integrity is strongly manifested in water decision-making, and the level of integrity plays a critical role in deciding the outcomes of decision-making, that is, who gets what water, when and how. In many countries, fragmented institutions obstruct accountability in a sector with high investment and aid flows, making the water sector particularly vulnerable to corruption. Governance failures such as corruption can take place at multiple levels and traverse all water uses, incurring huge cost for societies, environment and human development. This chapter provides insights into the role of integrity to improve governance and suggests an apparent need to include integrity and anticorruption-related issues in the analysis of and policy responses to water crises. Accountability in water supply services is used as an example to outline challenges and opportunities for strengthening integrity.
\end{abstract}

Keywords Integrity $•$ Accountability $\bullet$ Governance $•$ Anti-Corruption $•$ Water - Water Services

\subsection{Introduction: There Is an Elephant in the Room}

Water crises are not primarily driven by water resource scarcity but by governance failures. Many factors can affect the overall effectiveness and efficiency of the water sector, such as systemic institutional inefficiency, limited staff capacities, scarce financial resources, inappropriately set planning priorities, inadequate and poorly maintained infrastructure and political instability. However, the roots, magnitude and consequences of the lack of integrity in water governance are some of the very important but much less well-known and addressed aspects. Low integrity and high levels of corruption are strong indicators that something is wrong with the governance system. Although the lack of integrity is far from unique to the water sector, water management is vulnerable to corruption, and such practices have dire

H. Tropp $(\bowtie) \bullet$ A. Jiménez $\bullet$ H. Le Deunff

Stockholm International Water Institute (SIWI), Linnégatan 87A, 10055 Stockholm, Sweden

e-mail: hakan.tropp@siwi.org 
consequences for sustainable, efficient and equitable water use, access and allocation. It has contributed to severe limitations in water reform implementation where processes of decentralisation and privatisation sometimes rather have opened up for new groups to exploit the system, despite the fact that arguments of better transparency and accountability were used to institute such changes in the first place.

The risks associated with low integrity, such as corruption within institutions at the forefront to reform water resource management and deal with the water crisis, have to date been little recognised or studied. There is an urgent need to provide support to these institutions, which, despite the genuine commitment and honesty of their efforts to prevent corruption, often suffer from being new and poorly capacitated and working at new scales and under new policies and laws. Improved water integrity would go a long way to increase the institutional efficiency and effectiveness to make required water reform changes. Corruption is a challenge in many parts of the world. Importantly, many countries in so-called developing regions are doing much better than some European countries. For example, according to the Corruption Perception Index 2014, countries like Malaysia, Botswana, Namibia and Rwanda ranked higher than Bulgaria, Greece and Italy (Transparency International 2015).

Limited water-related integrity incurs huge costs for societies, in lives lost, stalling growth and degraded water resources. Corruption fuels unfair distributions of costs and benefits among different user groups or completely excludes certain groups of a particular water use. It can also be a strong driver to falling groundwater tables and diminishing ecosystem services due to unaccounted-for-water withdrawals of lakes and rivers. It increases transaction costs and implies very high investment risks for both public and private investors. In sum, increased sustainability, equity and efficiency of water resources and services allocation, access and use will in many places be very hard to come by, or attained at a much higher cost, without improving integrity. For example, it has been estimated that corruption in water and sanitation significantly increases the costs of reaching international water supply and sanitation targets (Transparency International 2008).

It is important to gain a better understanding of the links between corruption and policy outcomes. Most of the time policies and laws are not lacking; the problem is that they are not implemented. Key issues are how water institutions can break out of this non-implementation mentality and what measures can be taken to incentivise better adherence to policies, rules and regulations.

It is long overdue to start to speak about the elephant in the room - the politically sensitive and unspoken drivers and consequences of corruption in the water sectorand above all to make systematic and coherent efforts to improve water integrity. This chapter points towards a need to strongly include integrity and anticorruptionrelated issues in the analysis of and policy responses to water crises. Not only is there a need for changed behaviour among public and private water decisionmakers, service providers and users, but it is also high time for setting in place a strong research agenda to assess the impacts of corruption in water and to contextualise policy responses and interventions to improve water integrity. Increased investments in integrity can reap high returns in improved revenues, efficiency 
gains, equitable water distribution, increased infrastructure investments and social and economic development.

\subsection{High Integrity Risks in the Water Sector}

Governance failures such as corruption can take place in most facets of water management and traverse all water uses, such as irrigation, hydropower, infrastructure development, water supply and sanitation and water for environment. It can appear in many forms, from petty to grand-scale corruption - falsified water metre readings, skewed distribution of water use permits, illegal water connections and/or water outtakes (surface water and groundwater) for agriculture or households, public sector procurement processes, infrastructure development, policy capture by elites and many more. It can involve two or more actors and can take place, for example, within the public sector when funds are leaking out of budgets, kickbacks between public and private sectors in procurements and between service providers and consumers when water fees are not paid to the water utility or when water is illegally tapped (Stålgren 2006). Corruption affects all sectors, from education, health and forestry to transportation and many more (see, e.g. Edgardo Campos and Pradhan 2007). A survey in South Asia pointed to law enforcement authorities (police and judiciary systems) as the most corrupt public institutions, followed by land administration (Transparency International 2002). Similarly, the construction sector is deemed high risk for bribery and corruption. It is apparent that corruption in other sectors impacts how water is used and allocated. For example, in most countries access to land and land rights is the pathway to also have access to water resources and the right to use it. Disputes over land and water are often settled by the court system. Construction of infrastructure is common in relation to water storage, water distribution, urban and rural water services, hydropower, flood protection and wastewater treatment. As a result it is critical to consider water integrity in a broader context since it relates heavily to other sectors.

The water sector is vulnerable to corruption. For example, institutional fragmentation makes decision-making authority for water extremely dispersed across political and administrative boundaries and agencies, which creates many loopholes to exploit. The provision of water services is monopolised and involves large flows of public funds in a noncompetitive way. Large water projects are capital-intensive and complex, which makes procurement lucrative, manipulation difficult to detect and corruption more likely to occur. When these factors appear in systems characterised by limited openness, transparency and accountability, patronage and discretionary decision-making, risks turn into practices of corruption and other forms of rent-seeking behaviour.

Many countries in Africa and Asia are stepping up their efforts significantly to develop water-related infrastructure as a response to development needs and expected impacts of climate change. The Sustainable Development Solutions 
Network (SDSN) estimates that USD 1-3 trillion is needed in infrastructure investments in developing countries in order to meet intergenerational development needs. It comes with high water integrity risks associated with procurement of services, location and design that can threaten the very effectiveness of investments. The construction sector is ranked globally as one of the most vulnerable sectors to corruption (Transparency International 2005). The potential for large-scale corruption in infrastructure development can be so substantial that it skews policy-making towards the most "lucrative" investments and not those that are better for technical, social and economic reasons (Butterworth and de la Harpe 2009). Similar challenges have been identified in climate proofing new or already existing water infrastructure (Jacobson and Tropp 2010).

\subsection{The Consequences of Corruption}

The impact of corruption in water can be severe and reaches far beyond water use and allocation and water supply services since it ultimately threatens or delays development and can make it more costly to achieve. Many times poor people are those worst affected since it hampers development of public services and skews natural resource allocation towards those with political clout and economic influence. In cases where corruption is endemic, the system becomes almost selfperpetuating and puts people and organisations between a rock and a hard place. For a farmer, not paying a bribe for water access can be the difference between having food on the table and not.

The general research on corruption concludes that it lowers investments and hampers fair competition among businesses. It undermines the rule of law, spreads mistrust and undermines the legitimacy of government institutions. It cripples the public sector to provide acceptable services to the public, such as education, health and water supplies. It causes misallocation of public funds as well as natural resources to the detriment of social justice and economic growth. Corruption systematically undermines sustainable development since it weakens environmental protection and undermines efforts to reduce income inequality and poverty (see, e.g. Edgardo Campos and Pradhan 2007; Stålgren 2006).

The lack of integrity has dire consequences for water, its uses and allocations. The following examples are provided:

- It undermines water reforms and their implementation. For example, it will be much harder to realise elements of integrated water resource management. In fact, if issues of transparency and accountability are not addressed, reforms such as decentralisation of decision-making can have perverse effects.

- It siphons off scarce monetary resources and diminishes a country's prospects for providing water and sanitation for all or to improve water storage. It leads to inefficient and unequal allocation and distribution of water resources and related 
services. It also contributes to increased water pollution and overabstraction of groundwater and surface water.

Various estimates of the costs of corruption are underestimations since they do not take into account secondary social and economic impacts or opportunity costs of corruption. For example, the costs in terms of health and loss of income-earning opportunities for poor people being locked out of certain water uses can be extremely high. It can result in loss of harvest or fewer educational opportunities for girls if they have to walk even longer distances to collect household water. While this can be observed at micro-level, it is difficult to aggregate the social and developmental impacts at macro-level. Costs of global corruption as calculated by, for example, the World Bank do not take into account opportunity costs of corruption to reduce poverty and inequalities, such as through improved access to water services. Nor does it contain costs of health impacts, environmental degradation, poor construction, inflated prices, etc. that can follow in the trail of corrupt behaviour. Kenny (2007) made use of indirect impacts to estimate the actual costs of kickbacks and cartels in some South Asian cities and found that it inflated the price of a sustainable water connection by $25-45 \%$.

It is clear that lack of integrity in the form of corruption has many detrimental impacts on society and development. While there are many narratives on corruption and how it impacts micro-levels, there is a lack of more systematic macro-level data. Due to the nature of corruption, it is difficult to collect data on the micro- and macro-economic, social and opportunity costs of corruption. Favours are normally exchanged behind closed doors with the intent to leave as few traces as possible. Finding and interpreting data is often a matter of building trust and endless corroboration and triangulation of data. In many cases there can be high individual and professional risks to research corruption issues.

\subsection{Linking Governance and Integrity}

Integrity has emerged as a new concept in the water sector, which is critical to address in order to improve water governance and achieve more sustainable water development. Integrity is often used as a euphemism for corruption. Water integrity is defined as the adherence of water stakeholders and institutions to governance principles of transparency, accountability and participation, based on core values of honesty, equity and professionalism. In a more practical sense, integrity can refer to how well governance regimes or systems adhere to the rule of law, predictability in decision-making procedures and outcomes, and whether decisions hold up to public scrutiny and to what extent they can withstand different types of vested interests and corrupt practices. Corruption in water is here used as a particular case to highlight issues of water integrity. Integrity aspects are very important for water use decisionmaking, and the level of integrity plays a critical role in the quality of governance that decides the outcomes of decision-making, that is, who gets what water, when 
and how. Importantly, governance is a neutral concept, and in cases where corruption is widespread, it may actually be how that particular governance system functions.

Accountability in water supply services is here used as an example to outline some challenges and opportunities for strengthening integrity. Accountability must be part of the relationship among policy-makers, service providers and clients. As a result, increased emphasis has been placed on strengthening the ability of citizens, civil society organisations and other non-state actors to hold local governments accountable for their commitments to improve service delivery and make them more responsive to citizens' needs. It is crucial to build capacity in local governments to not only deliver services effectively but to also enhance their ability to engage citizens by fostering dialogue and participation.

\subsection{Approaches to Water Integrity}

The literature reflects only slight growth in studies on water integrity-related issues, such as on analysing the dynamics of corruption, mismanagement and poor governance in the water sector. Many of the corruption risks are generically well known, but we know far less about how corruption plays out in certain contexts and what type of incentives through social pressures, policy and legal measures can be effectively applied.

There are three main approaches to corruption and related anticorruption measures (see UNDP 2011). The first - and the most common view - is characterised as the "rotten-apple" perspective. Corruption is seen as the misbehaviour and moral misconduct of individual civil servants and less as something systematic or ingrained in the system. Well-functioning upward accountability systems and various checks and balances along with legal measures are considered going a long way towards minimising corruption. The second view is related to rent-seeking behaviour of civil servants. Civil servants are considered opportunistic and self-serving which increases the risk of corruption. More controls and checks and balances are not primarily seen as solutions but rather changes such as privatising services or contracting out more public services to the private sector. However, experience suggests that there are big corruption risks in relation to processes of privatisation and contracting between public and private sectors. Consequently improved accountability and transparency are still important factors when the private sector is increasingly engaged with, for example, water services provision. The third approach considers corruption in light of complex and dynamic social, political and economic processes. Corruption is not only something that goes on between individuals but is embedded and institutionalised, and in some cases it is not an anomaly but how the system functions. Corruption is seen as power struggles between groups and a way of gaining control of and securing resources in society or policy capture. Some of the remedies suggested are, for example, improved social accountability that empowers civil society groups, such as water user or consumer groups to hold civil 
servants and elected politicians to account. It also presupposes an improved flow of and better access to information in society and free media.

Here a particular view is not chosen since it can be context specific and many times it may be a mix of these three approaches. It is clear that improved accountability is important for all of them to work. To date, much of the work to improve water integrity has been to prevent it from happening in the first place, that is, proposed measures have focused on improving the system and strengthening institutional set-ups.

In his seminal work on corruption in irrigation in India, Wade (1982) described how irrigation engineers were able to illicit significant revenues by controlling contracts and the distribution of water to the farmers and that it was part of a larger system, redistributing parts of revenue to higher-ranking public officials and politicians. Corruption was seen as a main reason for the poor performance of canalirrigated agriculture. Similar studies have been undertaken in Pakistan (Rinaudo 2002) to show how corruption determines water allocation and that it entails not only the rich and influential farmers but also powerless small-scale farmers. Another study pointed to the role of patronage and clientelistic linkages in petty corruption in Kazakhstan and grand-scale political capture in Chile as determinants of how water resources are allocated within agriculture (Warner et al. 2009). Similar patterns of patronage and clientelism linkages were found in urban water pollution and in the relations between NGOs and local authorities (Tropp 1998). Another study pointed to the high frequency of kickbacks to public officials and tampering with water fees in urban water supply in some major Indian cities, leading to big revenue losses (Davis 2004).

Principal-agent theory has been used to explore relational patterns between the "principal" (consumer or client) and the "agent" (the service provider) and the various types of exchanges (money, favours, nepotism) that can take place. Problems with principal-agent relations are related to suboptimal contracts and agreements (if they exist in the first place) between exchange partners, such as between local public officials and farmers for release of water to irrigated farming or between the service provider of household water and the consumer. A major problem that can be exploited is that the providers of the service normally have better information and knowledge of the service provision value chain as compared to the consumers of the services. This is a case of asymmetric information, where the information advantage by service providers can be misused for corruption and other rent-seeking behaviours, such as overpricing. In contexts where regulation enforcement is lax and where there is little transparency and openness to share information, the risks of corrupt behaviour will increase. The provision of water services is considered close to a natural monopoly; hence, there is very little scope for replacing the water service provider with another one. This lack of competition will further increase risks of, for example, corruption and overpricing ${ }^{1}$ (see, e.g. Huppert 2002).

\footnotetext{
${ }^{1}$ The informal water service sector contains many small-scale operators and can be competitive. However, there are many accounts where local providers divide up local markets, creating "water
} 
In the above cases, important features are patron-client-like relations and that information is tilted towards the advantage of government agencies. Many times public officials might be tempted to make power and information asymmetries work to their advantage to reap illicit incomes. Patronage and clientelism makes decision-making discretionary and allows for personal motivations of public officials and politicians to seek out illicit income-earning opportunities.

The improvement of accountability would require that relevant information is accessible to the public and that stakeholders can take part in decision-making processes. What makes the situation more complex is that civil society is often weakly organised. Politics can also slow, skew or stall these processes, as government departments and individuals try to prevent or impede actions that are seen to threaten their own power and authority.

\subsection{Horizontal and Vertical Governance Interface}

While horizontal work on strengthening governance has been ongoing for many years in areas such as putting in place anticorruption commissions, special prosecutors and ombudsman, the water sector itself has at large been turning a blind eye to integrity and anticorruption issues. It was not until 2005 that these issues started to receive international recognition and attention, and more systematic counterreactions were being developed through initiatives such as the Water Integrity Network.

The experience of setting in place national anticorruption commissions, special anticorruption prosecutors and ombudsman has had very few benefits or even negative impacts (Heilbrunn 2004). The development of anticorruption commissions and other similar bodies has frequently been demanded by donors but not owned by policy-makers and implementing agencies. Moreover, in many cases the establishment of such commissions has been used as an excuse to avoid and ignore needs for deeper reforms. A worst case scenario is that anticorruption institutions are misused in national power struggles to discredit political rivals. Anticorruption commissions have been plagued by lack of independence from the government, limited budgetary support and investigative powers and unclear procedures in forwarding cases to prosecution.

It is critical to continue to address corruption from a horizontal and holistic governance angle, but ultimately any national corruption strategy needs to be implemented within sectors. A targeted sector approach owned and driven by the sector can be more practical and realistic to actually make headway on anticorruption measures and improved governance. Successful sector work to improve integrity can thus have an important snowballing effect.

The long-term viability of a sector approach is thus supported by efforts that strengthen governance in the interfaces of horizontal and vertical governance.

oligarchs". There are also several accounts from many slum areas in cities where water services are controlled by local organised crime. 
Improved water integrity also requires cross sector work and collaborations since water use cuts across many other sectors.

\subsection{Improving Accountability in Water Service Delivery}

Integrity is about improving transparency, accountability and participation in the service delivery framework, which has significant impacts on how services are delivered in practice.

In most countries, institutional arrangements for water service delivery are in place: policies, plans and institutions exist, yet performance remains poor. In this context, accountability, which is about improving the quality of relationships between the different stakeholders in service delivery arrangements, is a key element to make these institutional arrangements function as intended. Accountability is about coming to grips with institutional deficiencies, through implementing the allocated mandates, roles and responsibilities as outlined in, for example, rules and regulations. Some evidence supports these statements. An evaluation report by the European Union of 23 water supply and sanitation projects in sub-Saharan Africa found that although equipment was generally installed as planned, fewer than half of the projects delivered results meeting the needs of beneficiaries. It was suggested that a majority of these projects were potentially sustainable in the sense of using standard technologies and local materials, but governance aspects were the key weakness for continuous service (European Court of Auditors 2012). In another recent Overseas Development Institute (ODI) research project focused on challenges to service delivery in the African context, three main constraints for service delivery were identified: incoherent policies, poor top-down disciplines and limited bottom-up accountability relationships, and limited scope for problem-solving and local collective action (Tavakoli et al. 2013).

Transparency and participation contribute to improved accountability. Transparency refers to openness of governance processes and free access to official information. Increased access to information enables citizens to scrutinise the work of government, and more transparency can put pressure on government officials to be accountable, perform better and avoid corruption (González de Asís et al. 2009). Participation refers to the opportunity for citizens to provide informed, timely and meaningful input and influence decisions at various levels. It also refers to the mechanisms used by citizens to express themselves and to influence decisions and processes in the political, economic and social sphere.

Accountability have been identified as a key enabling factor for improved governance of water, but the challenge remains to find the best ways to strengthen accountability links in the water sector (Sohail and Cavill 2007). Acknowledging that institutional inertia is at the core of the problem, many external support agencies (donors, international organisations, NGOs, etc.) have targeted their support to national accountability on strengthening relationships between actors. How can external support strengthen accountability links in a meaningful way without distorting national accountability frameworks? This section discusses the potential roles and challenges of accountability support, based on experiences in the Water 
Sanitation and Hygiene (WASH) sector. The first part attempts to define accountability, before "unpacking" the key concepts into different objectives. The section ends with a discussion about the challenges encountered in the implementation of different accountability support interventions.

\subsubsection{Defining Accountability Among Service Delivery Actors}

Accountability refers to sets of controls, counterweights and modes of supervision that make officials and institutions in the public and private sector answerable for their actions and ensures that sanctions are applied against poor performance, illegal acts and abuses of power. Well-functioning accountability mechanisms can help clarify the commitments of actors involved in water governance, lead to efficient management of fiscal resources, protect water resources and increase control over the actions of public and private stakeholders and ensure minimum quality standards (UNDP and SIWI 2013).

A combination of mechanisms can be put in place to operationalise the accountability principle (see Fig. 10.1). Horizontal accountability describes relationships where a state actor has the authority to demand explanations or impose penalties on another state actor. Horizontal oversight systems are thus based within the legal and justice system. They include mechanisms of internal oversight and checks and balances within an institution (internal control) or oversight and checks and balances of public institutions. Vertical accountability links citizens directly to the government. Vertical accountability exists when non-state actors such as the media, nongovernmental organisations or individuals place pressure on state actors for improved services. Traditionally, elections and the use of informal processes are the direct way to channel citizens" "voices" to exert pressure on policy-makers. Indirect forms of vertical channels include civic engagement, lobbying and mass mobilisation. Transversal or hybrid accountability refers to the participation of citizens and civil society (actors from the "vertical" accountability relationships) in horizontal (state-to-state) processes of accountability. This type of mechanism helps overcome the limited impact of traditional civil society methods, strengthens horizontal mechanisms of accountability and legitimises the inclusion of citizens in government oversight functions. The use of horizontal institutions by the public to improve accountability interactions between the state and water users can help develop civic engagement and foster the development of social accountability mechanisms. Social accountability describes mechanisms which involve civil society in holding duty bearers to account for the performance of service provision. Social accountability tools can be used both to hold public officials to account and to improve the accountability link between users and service providers. In addition, distinctions can be made between specific domains of accountability; in this sense, we talk about political, administrative, legal and financial accountability. 


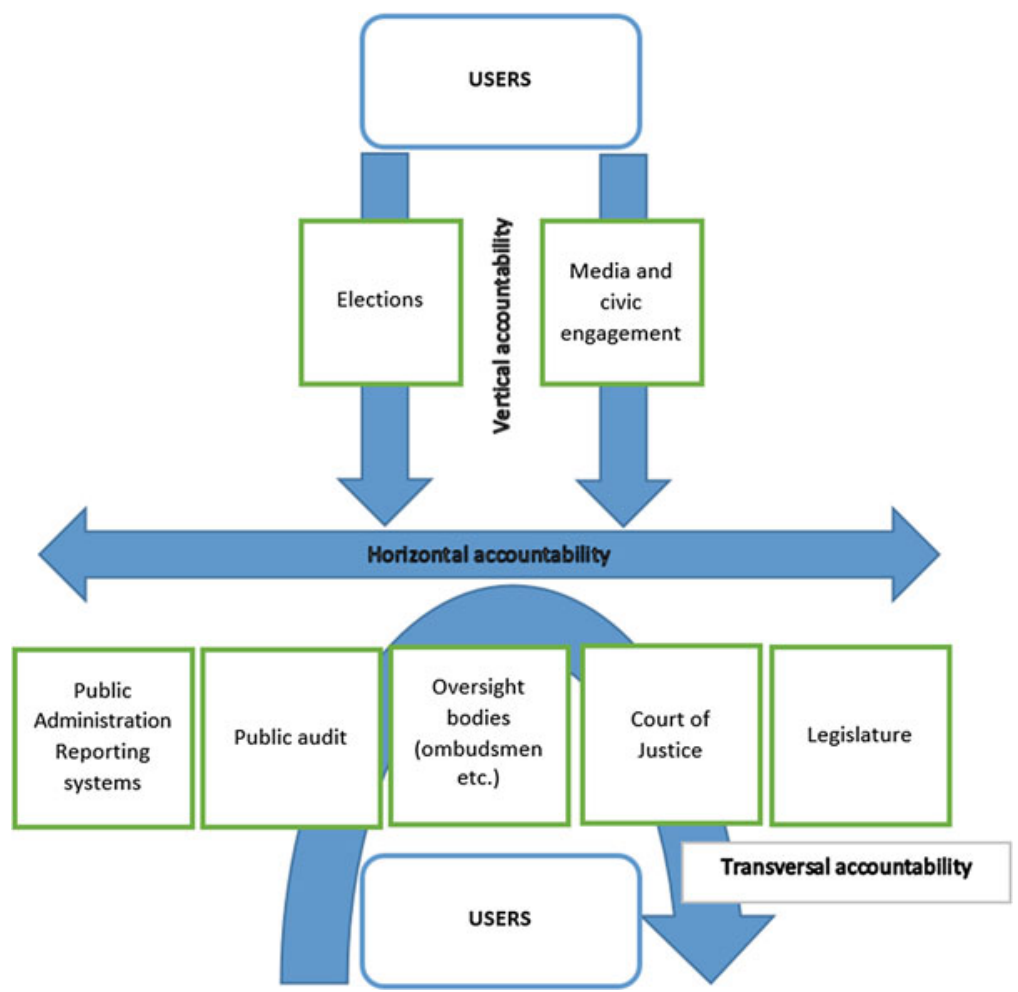

Fig. 10.1 Vertical, horizontal and transversal dimensions of accountability (Source: Own elaboration from UNIFEM 2008)

\subsubsection{Unpacking Accountability in Water Service Delivery}

The analysis of accountability addresses a wide range of interactions between multiple service delivery actors occurring at different levels. The human rights framework offers a useful way of understanding the accountability challenges by depicting the different dimensions of the accountability system into responsibility, answerability and enforceability (OHCHR 2013). Adapting this framework to the water sector (UNDP WGF/UNICEF 2015), we define three main levels of intervention:

(A) Defining the roles and enabling cooperation in service delivery. A precondition for accountability is that those in positions of authority (governments and service providers) have clearly defined duties and performance standards, enabling their behaviour to be assessed in a transparent and objective way. At the same time, users need to know their rights and obligations. Moreover, effective coordination mechanisms between different responsible parties need to be put in place. Promoting responsibility focuses on three different objectives: enhanc- 
ing policy coherence, providing clarity in the definition of responsibilities and improving coordination in the sector.

(B) Informing, consulting and including stakeholders in all stages of service delivery. The emphasis at this second level of intervention is that timely and accurate information is made available about service provision, such as the current status of services, the performance of service providers or the decisions about financial allocations. Spaces for interaction between users, services providers and government also need to be created to enable participants to explain, question, discuss and/or justify decisions. The three main objectives of support to greater answerability in service provision will be to enhance the flow of information and use of consumer feedback, to improve consumers' access to information and to create spaces for stakeholders' participation.

(C) Monitoring performance and supporting compliance and enforcement. The third level of intervention focuses on enforcing mechanisms, which aim to monitor and ensure compliance of public officials, service providers and institutions with established standards; to impose sanctions on officials and companies who do not comply; and to ensure that appropriate corrective and remedial actions are taken when required. Two main objectives can be identified for improving enforceability, namely, to establish or support the regulatory function and to strengthen external and internal control mechanisms.

\subsubsection{Challenges and Success Factors}

Accountability is not the responsibility of only one type of institution but involves all stakeholders of the water services, often in shifting roles (as duty bearers and rights holders), and it is influenced by a range of social and political factors. There are many possible entry points and approaches for promoting accountability in water service delivery, depending on the needs as well as the wider political and economic context in which accountability processes take place. However, research suggests that initiatives taken to support accountability relationships face a series of challenges suggesting that there is space for better fitted approaches. Much effort has been dedicated in recent decades to support the definition of clear policy frameworks and to enhance sector coordination in developing countries. The Paris Declaration on Aid Effectiveness (OECD 2005/2008) has also boosted this effort. More than one decade later, a few lessons can be learnt. Too often, policies promoted and adopted have been based on international blueprints and have not taken into consideration the reality of the country, drawing a picture that is too far removed from actual practice and possibilities of the country (OECD 2013), leading to poor implementation. External support agencies have also supported coordination mechanisms in many countries. However, trickle-down effects have been limited, and on many occasions, increased coordination at the national level has not improved benefits in terms of service delivery to citizens at the other end. Hence, policy processes cannot translate into improved responsibility unless authorities provide guidance 
and clarification on the general principles contained in policy documents by developing the necessary decrees, acts or laws. Moreover, information about policy and action needs to be made readily available to all stakeholders; in practice, policies often take years to be known at local levels of government or by end users. Finally, implementation of policies requires that public resources are allocated and that key actors have the necessary capacities to deliver. Very often, these conditions are not met. With regard to coordination among accountability actors in the water sector, the case of Uganda (SIWI/WIN/WSP 2012) offers important lessons in how these efforts have to be clearly linked to improved access to information, clear and measurable indicators and the establishment of feasible commitments for annual improvement.

Engaging stakeholders and increasing the flow of information and participation have been mainly supported through a social accountability approach, focusing on strengthening citizens' demand for improved transparency and performance. In certain cases, good short-term results have been announced with enthusiasm. However, in the long run, social accountability mechanisms need to be institutionalised and aligned with formal accountability mechanisms - and not compete with or undermine them. A typical example of this phenomenon can be found in the monitoring mechanisms of services based on users' collaboration in data collection. To sustain citizen mobilisation in the long run, interaction is vital as well as visible impacts. Findings in East Africa (SIWI 2013) point to the need to complement this type of tools empowering users with a parallel development of the capacity of water service providers and government to act upon the information collected. Support to accountability in the water sector involves interactions with political actors and politicised processes. In actions aiming to engage the population in order to improve answerability, a context-sensitive approach can entail addressing issues of privacy and security. In the same way, in certain contexts it might be necessary to invest time working to increase the political receptivity to citizens' demands and criticism to avoid serious risks for people and institutions. When the objective of the intervention is to build or improve the relationships across accountability actors, the main challenge is to link the stakeholder dialogue exercise with official decision-making processes. Development partners need to ensure that adequate resources are allocated for the completion of these dialogues, since they are often time and resource intensive, especially if inclusiveness is one of the objectives. Managing the expectations of dialogue participants is also crucial.

Opening up the political willingness for the establishment of regulatory functions in water services has proved to be a long and difficult process. Acceptance and understanding of the regulatory process by the consumers and other stakeholders and broad institutional support for the regulatory body is a first condition; once the institution is established, financial autonomy is required. The inclusion of citizens in the regulatory function (as, e.g. Water Watch Groups that inform the regulator directly through mobile phones) is a very interesting development of transversal accountability. Evidence from Zambia (SIWI 2008) shows that this type of cooperation can help raise the profile and public knowledge about the regulator and is a cost-effective source of information on sector performance for the regulator. 
Oversight institutions can also be general and not sector specific. Anticorruption agencies and other oversight institutions will require the presence of a strong judiciary, i.e. courts to back up their constitutional authority when prosecuting cases; moreover it is essential that "whistle-blowers" and ordinary citizens are protected from retribution.

\subsection{Some Lessons Learnt}

Accountability is a powerful entry point to improve water integrity and thus water governance. However, external support agencies face multiple challenges in their support to accountability. Experience shows that approaches financed by external actors can run the risk of remaining externally owned at least in the short to medium term. A critical condition for effective aid-funded activities is to analyse the incentive structures for accountability in order to identify and manage risks and opportunities in the political and administrative landscape and understand the societal demands and work through or in close contact with reform-minded top public officials. Another major challenge is to avoid a situation where accountability interventions substitute civil society initiatives to failing state capacity, which can lead to even more disorganisation of the service delivery framework. The support provided by external support agencies often tends to focus on participatory approaches. However, evidence confirms that without the threat of effective sanctions (and resulting impacts), citizen mobilisation is difficult to sustain in the long run. Similarly, as noted by the general literature on anticorruption, anticorruption reforms should not only target law enforcement, but rather public officials should be part of broader changes on how they interact with the public (Rose-Ackerman and Carrington 2013).

For external support agencies to tackle these risks and to achieve sustainable results, there is a need to broaden the scope of efforts. One first useful step is to ensure that support to accountability targets both social accountability mechanisms, aimed at increasing citizens' voice, and traditional accountability mechanisms, such as investigations, inspections and audits which can impose formal sanctions. Civil society organisations play a key role in demanding accountability, but weaknesses of the NGO sector in many aid-dependent countries can constrain the effectiveness of external support agency interventions. Many NGOs rely on external assistance while at the same time they need to develop credibility, local legitimacy and independence from the government. Donors will need to provide long-term support in a balanced way, without undermining the necessary commitment to local improvement while aiming at developing self-sustainable organisations.

An associated challenge to these processes is the long-term need to see reforms make changes on the ground, for users but also for politicians who want re-election and for external support agents who need to show short-term results to their constituencies. The next generation of accountability support will require a more politically informed understanding of the national context, more flexibility and patience 
from external support agencies, a capacity to work with the existing local fabric without making it overdependent on external actors and developing a long-term and open vision from national governments to increase the role of citizens in the public space.

\subsection{Conclusions}

Limited integrity manifested in corruption is a concern for the whole water sector which disproportionately affects the development of the most vulnerable countries. The implementation of water policies and the sustainable use and development of water are at high risk.

Experience suggests that functioning accountability systems are one important element to improve water integrity. To increase its impacts, there is a need to use accountability measures in more integrative ways, such as developing mutually supportive measures to strengthen social accountability and horizontal accountability between government agencies. Hence, if there are real risks of not only getting exposed but that exposure can also lead to legal actions, the likelihood of accountability measures gaining impacts is enhanced. This is clearly coupled with the need for a sector governance focus more strongly coupled with other national governance efforts to strengthen anticorruption commissions, procurement oversight agencies and judiciary systems.

Most research and development cooperation programming on water integrity and corruption thus far has focused on household water supply and irrigation. While, in general, there is an urgent need to intensify work in these areas, there is a sense of urgency to develop water integrity and anticorruption research and programming across water users and institutional fragmentations. For example, the much required water infrastructure investments in many developing countries are at high risk of corruption, which can affect their efficiency as well as potential investors backing out due to too high business risks.

Some are now starting to acknowledge the elephant in the room. The challenges raised by limited integrity and corruption in water management have long been recognised as important. What is new, however, is the increased awareness of the issue at the international and national levels. This recognition has sparked debates on how to tackle the problems and challenges associated with it. While integrity is still a highly sensitive social and political topic in many contexts and for development partners in particular, the use of water integrity and associated measures to promote transparency, accountability and participation can offer a constructive way forward to get around some of these sensitivities.

Improving integrity and reducing corruption is a means to an end. The objective of particular reforms and the characteristics of the political and socio-economic contexts in which they are implemented should guide the choice of the types of support measures put in place. It is critical to trace and assess the link between anticorruption measures and their outcomes. This is a very challenging task since this type 
of information is difficult to come by and information on costs and benefits of alternative options is frequently not available.

An urgent call is made for developing a strong research agenda on water integrity and anticorruption. In countries with malfunctioning governance systems, lack of integrity and high frequency of corrupt interactions is one of the single biggest governance issues to be resolved. Very modest resources have so far been devoted in the water sector to explore corruption hotspots, impacts and consequences and the type of measures that should be applied. To date, we know fairly little about the measures that work and in what contexts. Importantly, such research agendas should also move beyond the narrow focus on institutions to include the role of social pressures in minimising corruption.

\section{References}

Butterworth, J., \& De la Harpe, J. (2009). Grand designs: Corruption risks in major water infrastructure projects (p. 4). Bergen: Chr. Michelsen Institute (U4 Brief 2009:27).

Davis, J. (2004). Corruption in public service delivery: Experience from South Asia's water and sanitation sector. World Development, 32(1), 53-71.

Edgardo Campos, J., \& Pradhan, S. (Eds.). (2007). The many faces of corruption: Tracking vulnerabilities at the sector level. Washington, DC: The International Bank for Reconstruction and Development/World Bank.

European Court of Auditors. (2012). European Union development assistance for drinking water supply and basic sanitation in Sub-Saharan countries, Special Report No. 13, Luxembourg. http://www.eca.europa.eu/Lists/ECADocuments/SR12_13/SR12_13_EN.PDF

González de Asis., et al. (2009). Improving transparency, integrity, and accountability in water supply and sanitation. The World Bank Institute and Transparency International. http://documents.worldbank.org/curated/en/2009/01/10546832/improving-transparency-integrityaccountability-water-supply-sanitation-action-learning-experiences

Heilbrunn, J. R. (2004). Anti-corruption commissions: Panacea or real medicine to fight corruption? Washington, DC: The World Bank.

Huppert, W. (2002). "Principal-agent" problems in irrigation - Inviting rent seeking and corruption. Quarterly Journal of International Agriculture, 41(1/2), 99-118.

Jacobson, M., \& Tropp, H. (2010). Addressing corruption in climate change water adaptation. Reviews in Environmental Science and Biotechnology, 9, 81-86.

Kenny, C. (2007). Infrastructure governance and corruption: Where next? (World Bank Policy Research Working Paper 4331). Washington, DC: World Bank.

OECD. (2005/2008). Paris declaration on aid effectiveness and the Accra agenda for action. Paris: OECD Publishing. http://www.oecd.org/dac/effectiveness/parisdeclarationandaccraagendaforaction.htm

OECD. (2013). Accountability and democratic governance: Orientations and principles for development. Paris: OECD Publishing. http://www.oecd.org/publications/accountability-anddemocratic-governance-9789264183636-en.htm

Rinaudo, J. D. (2002). Corruption and allocation of water: The case of public irrigation in Pakistan. Water Policy, 4(5), 405-422.

Rose-Ackerman, S., \& Carrington, P. D. (Eds.). (2013). Anti-corruption policy: Can international actors play a constructive role? Durham: Carolina Academic Press.

SIWI/WIN/WSP. (2012). Promoting transparency, integrity and accountability in the water and sanitation sector in Uganda. http://www.watergovernance.org/documents/Resources/Reports/ WIN_WSP_Uganda_report.pdf 
Sohail, M., \& Cavill, S. (2007). Accountability arrangements to combat corruption - Case study synthesis report and case study survey reports (Partnering to combat corruption series). Loughborough: WEDC, Loughborough University.

Stålgren, P. (2006). Corruption in the water sector: Causes, consequences and potential reform (Swedish water house policy brief no. 4). Stockholm: SIWI.

Stockholm International Water Institute. (2008). Mapping of integrity and accountability in water activities and relevant capacities in the SADC-region. http://www.siwi.org/publication/ mapping-of-integrity-and-accountability-in-water-activities-and-relevant-capacities-in-thesadc-region/

Stockholm International Water Institute (SIWI). (2013). Using information and communication technology to improve governance and cooperation. In: Cooperation for a water wise world, World Water Report 2013. www.siwi.org/Resources/Reports/2013_WWW_Report_web.pdf

Tavakoli, H., Simson, R., Tilley, H., \& Booth, D. (2013). Unblocking results: Using aid to address governance constraints in public service delivery. Overseas Development Institute (ODI). http://www.odi.org/sites/odi.org.uk/files/odi-assets/publications-opinion-files/8409.pdf

Transparency International. (2002). South Asia - Insights and benchmarks from citizen feedback surveys in five countries. Berlin: Transparency International.

Transparency International. (2005). Global corruption report 2005: Corruption in construction and post-conflict reconstruction. www.transparency.org/publications/gcr

Transparency International. (2008). Global corruption report 2008 - Corruption in the water sector. Cambridge: Cambridge University Press.

Transparency International. (2015). Corruption Perception Index for 2014. https://www.transparency.org/cpi2014

Tropp, H. (1998). Patronage, politics and pollution - Precarious NGO-state relationships: Urban environmental issues in South India (Linköping Studies in Arts and Science 182). Linköping: Linköping University.

United Nations Development Fund for Women (UNIFEM). (2008). Who answers to women? Gender and accountability, progress of the world's women, 2008/2009. http://www.unifem. org/progress/2008/media/POWW08_Report_Full_Text.pdf

United Nations Development Programme - Water Governance Facility/UNICEF. (2015). Accountability in WASH: Explaining the concept. Accountability for sustainability partnership: UNDP Water Governance Facility at SIWI and UNICEF, Stockholm and New York. http://www.watergovernance.org/Accountability-for-Sustainability

United Nations Development Programme (UNDP). (2011). Fighting corruption in the water sector: Methods, tools and good practices. New York: UNDP.

United Nations Development Programme (UNDP)., \& Stockholm International Water Institute (SIWI). (2013). User's guide on assessing water governance. New York: UNDP. Jean-Daniel Rinaudo.

United Nations Office of the High Commissioner for Human Rights (OHCHR). (2013). Who will be accountable? Human Rights and the Post-2015 Development Agenda. http://www.ohchr. org/Documents/Publications/WhoWillBeAccountable.pdf

Wade, R. (1982). The system of administrative and political corruption: Canal irrigation in South India. Journal of Development Studies, 18(3), 287-328.

Warner, J., Butterworth, J., Wegerich, K., Mora Vallejo, A., Martinez, G., Gouet, C., \& Visscher, J. T. (2009). Corruption risks in water licensing with case studies from Chile and Kazakhstan (Swedish water house report no. 27). Stockholm: SIWI. 
Open Access This chapter is distributed under the terms of the Creative Commons AttributionNoncommercial 2.5 License (http://creativecommons.org/licenses/by-nc/2.5/) which permits any noncommercial use, distribution, and reproduction in any medium, provided the original author(s) and source are credited.

The images or other third party material in this chapter are included in the work's Creative Commons license, unless indicated otherwise in the credit line; if such material is not included in the work's Creative Commons license and the respective action is not permitted by statutory regulation, users will need to obtain permission from the license holder to duplicate, adapt or reproduce the material.

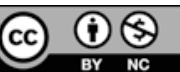

